\title{
What factors are predictive of surgical resection and survival from localised non- small cell lung cancer?
}

David C Currow
MPH, PhD, FRACP Chief Cancer Officer and Chief Executive Officer

Hui You BEngSc, MInfSc, MAppStats Biostatistician² Sanchia Aranda
PhD, MN Director, Cancer Services an Information

Brian C McCaughan MBBS, FRACS Cardiothoracic Surgeon

Stephen Morrell $\mathrm{PhD}, \mathrm{BA}, \mathrm{BSC}$ Epidemiologist, ${ }^{2}$ and Senio

Research Fellow ${ }^{4}$

Deborah F Baker BAppSc, MPH, GradDipAppEpid Manager $^{2}$

Richard Walton Biostatistician and Manager ${ }^{2}$

David M Roder MPH, DDSc(Epid)

Professor of Cancer Epidemiology and Population Health

1 Cancer Institute NSW Sydney, NSW.

2 Information Analysis Unit, Cancer Institute NSW. Sydney, NSW.

3 Royal Prince Alfred Hospital,

Sydney, NSW

4 School of Public Health and Community Medicine University of

New South Wales,

Sydney, NSW.

5 School of Population Health University of South Australia, Adelaide, SA.

david.roder@ unisa.edu.au

MJA 2014; 201: 475-480 doi: $10.5694 / \mathrm{mja} 14.00365$ ung cancer is the leading cause of cancer death, accounting annually for about 8100 deaths in Australia ${ }^{1}$ and 1.4 million deaths worldwide. ${ }^{2}$ Around $90 \%$ of lung cancers among men and $65 \%$ of lung cancers among women in Australia are attributed to tobacco smoking, which underlines the importance of tobacco control. ${ }^{3}$

Trends in age-standardised lung cancer mortality since the mid 1980s have shown an approximate 30\% increase among women and a $40 \%$ reduction among men, reflecting contrasting trends in tobacco smoking around three decades earlier. ${ }^{1,4}$ While risk of death among lung cancer patients has decreased, about $72 \%$ of Australian patients die of this disease within 1 year of diagnosis, and about $86 \%$ within 5 years. ${ }^{5}$

New South Wales, the study site, includes 35\% of the Australian population. A comparison of patient outcomes in NSW, Norway, Denmark, the United Kingdom, Canada and Sweden found differences in 1-year stage-specific survivals, prompting questions about treatment differences. ${ }^{6}$ For localised cases, the 1-year death rate for NSW was higher than for comparison populations. ${ }^{6}$ Although it is suspected that coding differences accounted for this finding, this is uncertain. It is important to explore underlying differences in death rates and determine whether opportunities for improving outcomes exist.

Unique for Australia, extent of disease is recorded routinely by the NSW Central Cancer Registry (NSWCCR). In this study, we explore clinical and non-clinical predictors of death among patients with localised nonsmall cell lung cancer (NSCLC), focusing on surgical resection. Cancer Council Australia/National Health and Medical Research Council and other guidelines indicate that surgical resection is the treatment of choice for localised NSCLC. ${ }^{-10}$ This is based on observational studies that showed

Abstract

Objective: To investigate opportunities to reduce lung cancer mortality after diagnosis of localised non-small cell lung cancer (NSCLC) in New South Wales through surgical resection.

Design, patients and setting: In this cohort study, resection rates and lung cancer mortality risk were explored using multivariate logistic regression and competing risk regression, respectively. Data for 3040 patients were extracted from the NSW Central Cancer Registry for the diagnostic period 1 January 2003 to 31 December 2007. Subset analyses for patients at low surgical risk indicated resection rates and outcomes under ideal circumstances.

Main outcome measures: Resection rates and lung cancer mortality.

Results: The resection rate in NSW was estimated to be between 38\% and $43 \%$, peaking at $59 \%$ by local health district (LHD) of residence. Not having a resection was associated with older age, lower socioeconomic status, lack of private health insurance, and residence by LHD. Adjusted 5-year cumulated probabilities of death were $76 \%$ in absence of resection, $30 \%$ for wedge resection, $18 \%$ for segmental resection, $22 \%$ for lobectomy and $45 \%$ for pneumonectomy. Of 255 "low surgical risk" patients, $71 \%$ had a resection. Those not receiving a resection had a higher probability of death (adjusted subhazard ratio, 14.1; $95 \% \mathrm{Cl}, 7.2-27.5$ ). If the low overall resection rate of $38 \%-43 \%$ in NSW were increased to 59\% (the highest LHD resection rate), the proportion of all patients with localised NSCLC dying of NSCLC in the 5 years from diagnosis would decrease by about 10\%, based on differences in probabilities of death by resection estimated in this study.

Conclusions: Potential exists to reduce deaths from NSCLC in NSW through increased resection.

higher survival rates after treatment by resection. ${ }^{10-13}$

Localised cases comprise around $30 \%$ of all NSCLC cases of known stage in NSW. ${ }^{6}$

In this study, we aimed to explore predictors of lung cancer death in localised NSCLC cases, resection rates, predictors of resection, and differences in death rates between resected and non-resected cases. The null hypothesis is that there is no difference in probability of death between NSCLC patients having and not having a resection.

\section{Methods}

Cumulative probabilities of lung cancer death were estimated for NSCLC cases recorded by the NSWCCR and diagnosed at a localised stage between 1 January 2003 and 31 December 2007 $(n=3040)$. Information on dates and causes of death was obtained from the NSW Registry of Births, Deaths and Marriages, and the National Death
Index at the Australian Institute of Health and Welfare for the period to 31 December 2008. ${ }^{5}$ Probability of death was compared by sociodemographic, patient and cancer characteristics and according to treatment by resection within 6 months of diagnosis.

Resection data were obtained through data linkage between the NSWCCR and the NSW Admitted Patient Data Collection (covering public and private hospitals). Overall, 2987 cases were linked successfully. Of the 53 cases not linked, 24 patients had been admitted to nursing homes or similar facilities where resections were not performed. The remaining 29 patients were assumed not to have had a resection for the purposes of this study.

Subset analyses of survival were undertaken for patients with NSCLC considered to be at low surgical risk based on age ( $<70$ years at diagnosis), absence of comorbidity, cell type (adenocarcinoma) and location (tumour 
confined to upper, middle or lower lobe), to determine the resection rate and case outcomes under "ideal circumstances".

\section{Data sources and items}

The NSWCCR is a population-based registry receiving mandated cancer notifications. Operational details are described in the Appendix (online at mja.com.au) and previous reports. ${ }^{14}$ Registry data for localised lung cancer (International Classification of Diseases for Oncology, 3rd edition [ICD-O-3]; C34) were used to classify cases by: (1) demographic characteristic - age at diagnosis, sex, country of birth, 15,16 geographic remoteness of residence, ${ }^{17}$ Australian Bureau of Statistics Socio-Economic Indexes for Areas (SEIFA) Index of Relative SocioEconomic Disadvantage for residential area, ${ }^{18}$ and local health district (LHD) of residence (there are eight metropolitan and seven rural and regional LHDs in NSW responsible for providing health services); and (2) histology type - adenocarcinoma, squamous cell carcinoma, large cell carcinoma, and other types, using standard ICD-O-3 morphology codes (see Appendix). ${ }^{15}$

Only localised cases diagnosed in 2003-2007 were included (ie, cancers confined to the lung, equating with TNM [tumour-node-metastases] stage $1 \mathrm{~A}$ and $1 \mathrm{~B}^{19}$ ). Hospital data were used to classify cases by: (1) comorbidity status using combined Charlson Comorbidity Index scores for up to 5 years before cancer diagnosis;,20 (2) resection type defined as wedge, segmental, lobectomy or pneumonectomy; $;^{16}$ and (3) payment status categorised as public or private (or Veterans' Affairs), using the first payment for the lung cancer management.

\section{Data linkage}

NSWCCR and hospital patient data were linked by the Centre for Health Record Linkage, ${ }^{21,22}$ and de-identified linked data files were forwarded to the data analyst. The linking protocols are described elsewhere. ${ }^{21,22}$

Approval for the study was obtained from the NSW Population and Health Services Research Ethics Committee (reference no. 2009/04/150).

\section{Statistical analysis}

Cross-tabulations were used initially to explore associations of resection with sociodemographic, patient and cancer characteristics, and comorbidity status. Multiple logistic regression analysis was then used to determine statistically significant (set at $P<0.05$ ) predictor variables for resection. In addition, relative odds (ie, odds ratios) with $95 \%$ confidence intervals were calculated to explore associations of individual variable categories with resection. ${ }^{23}$

Competing risk regression modelling indicated subhazard ratios (SHRs) for lung cancer death from time of diagnosis to death (in months) or to 31 December 2008, whichever occurred first, in the presence of nonlung cancer death as the competing event. ${ }^{24}$ SHRs were determined for resection types and patients not having a resection, adjusting for demographic, histological and comorbidity characteristics. The competing risk regression analysis was used to determine statistically significant predictor variables for lung cancer death. In addition, SHRs with 95\% confidence intervals were used to explore associations of individual variable categories with lung cancer death. For resection cases, duration (months) from diagnosis to resection and annual resection volume of hospital were investigated as an outcome predictor. ${ }^{25}$

Collinearity assumptions were tested and log-normal plots examined to test proportionality assumptions in competing risk regression models. ${ }^{23,24}$ Missing values of predictor variables were coded as dummy variables. The stability of SHR estimates was tested in repeated modelling by restricting the data to cases without missing values. Sensitivity analysis was undertaken using all-cause mortality rather than lung cancer death as the outcome variable. Adjusted cumulative probabilities of lung cancer death were derived from the competing risk regression base model for periods of up to 5 years from diagnosis. ${ }^{24}$ Stata release 12 (StataCorp) was used for all analyses.
Results

Comparisons of resected versus non-resected cases

Of all 3040 cases, 1168 (38.4\%) were treated by resection (Box 1). The peak rate by LHD was 59.1\% (65/110). If data for six LHDs with interstate borders were excluded due to potential underrecording because of treatment outside NSW, the resection rate was $42.6 \%(1072 / 2517)$. Of all 1168 resections, 102 were wedge (8.7\%), 271 were segmental (23.2\%), 738 were lobectomies $(63.2 \%)$, and 57 were pneumonectomies (4.9\%).

Multiple logistic regression analysis indicated a lower probability of resection among older patients compared with the reference age group of under 60 years; $38 \%$ lower for $70-79$ years and $80 \%$ lower for $\geqslant 80$ years in the main analysis (Box 1). Odds of resection were higher for privately insured patients (or those with Veterans' Affairs coverage), and lower for lower socioeconomic quintiles 3-5 compared with quintile 1 , cancers in the main bronchus than those in other sites, squamous and large cell carcinomas than adenocarcinomas, and cases with comorbidity. One LHD presented an elevated probability of resection (relative odds, 2.45; 95\% CI, 1.36-4.41) compared with the reference LHD.

When the six border LHDs were excluded, similar results presented, including lower odds of resection for socioeconomic quintiles 3-5 compared with quintile 1, although statistical significance was not reached for quintiles $4-5$ (relative odds, 0.67 ; 95\% CI, 0.44-1.03 for quintile 4; and 0.65 ; 95\% CI, $0.42-1.01$ for quintile 5).

\section{Probability of lung cancer death}

The probability of lung cancer death by period from diagnosis, as indicated by competing risk regression, was $24.7 \%$ at 12 months, $37.8 \%$ at 24 months, $45.1 \%$ at 36 months, $48.8 \%$ at 48 months and $52.3 \%$ at 60 months.

The competing risk model, adjusted for other variables, indicated the following statistically significant differences: a higher probability of lung cancer death for older ages, for large cell than adenocarcinomas, and compared with lobectomy, for cases having no resection, a wedge resection or 
pneumonectomy (Box 2; Box 3). The model predicted an adjusted 5-year probability of lung cancer death of $76 \%$ in the absence of resection, $30 \%$ for wedge resection, $18 \%$ for segmental resection, $22 \%$ for lobectomy and $45 \%$ for pneumonectomy. One LHD had a lower death probability
(SHR, 0.61; 95\% CI, 0.44-0.86) compared with the reference LHD. A lower death probability was also evident for the privately insured (or with Veterans' Affairs coverage) and patients born outside Australia. While lower socioeconomic status was not associated with higher
1 Resection rate and adjusted relative odds of resection for localised non-small cell lung cancers diagnosed in New South Wales, 2003-2007*

\begin{tabular}{|c|c|c|c|c|}
\hline Characteristic & No. & $\begin{array}{l}\text { Resection } \\
\text { rate, \% }\end{array}$ & $\begin{array}{c}P \text { for test }{ }^{\dagger} \\
\text { (unadjusted) }\end{array}$ & $\begin{array}{l}\text { Adjusted } ¥ \text { relative } \\
\text { odds of resection } \\
(95 \% \mathrm{Cl})\end{array}$ \\
\hline \multicolumn{5}{|l|}{ Age at diagnosis (years) } \\
\hline$<60$ & 490 & $52.7 \%$ & $<0.001$ & 1.00 (reference) \\
\hline $60-69$ & 832 & $48.3 \%$ & & $0.93(0.71-1.23)$ \\
\hline $70-79$ & 1091 & $37.2 \%$ & & $0.62(0.48-0.82)$ \\
\hline$\geqslant 80$ & 627 & $16.3 \%$ & & $0.20(0.14-0.28)$ \\
\hline \multicolumn{5}{|l|}{ Sex } \\
\hline Male & 1901 & $36.9 \%$ & 0.024 & 1.00 (reference) \\
\hline Female & 1139 & $41.0 \%$ & & $1.05(0.87-1.27)$ \\
\hline \multicolumn{5}{|c|}{ Public/private payment status } \\
\hline Public & 1918 & $33.5 \%$ & $<0.001$ & 1.00 (reference) \\
\hline Private (+ Veterans' Affairs) & 1082 & $48.2 \%$ & & $2.08(1.70-2.54)$ \\
\hline Unknown & 40 & {$[7.5 \%]$} & & $0.09(0.02-0.35)$ \\
\hline \multicolumn{5}{|l|}{ Remoteness (residence) } \\
\hline Major city & 1747 & $42.7 \%$ & $<0.001$ & 1.00 (reference) \\
\hline Inner regional & 834 & $35.6 \%$ & & $1.00(0.76-1.32)$ \\
\hline Outer regional & 411 & $26.0 \%$ & & $1.00(0.64-1.56)$ \\
\hline Remote/very remote & 48 & $37.5 \%$ & & $1.47(0.62-3.50)$ \\
\hline \multicolumn{5}{|c|}{ Socio-Economic Indexes for Areas quintile } \\
\hline 1 (least disadvantaged) & 508 & $45.5 \%$ & $<0.001$ & 1.00 (reference) \\
\hline 2 & 502 & $44.0 \%$ & & $0.74(0.52-1.06)$ \\
\hline 3 & 624 & $32.9 \%$ & & $0.58(0.39-0.87)$ \\
\hline 4 & 744 & $35.5 \%$ & & $0.63(0.41-0.95)$ \\
\hline 5 (most disadvantaged) & 662 & $37.3 \%$ & & $0.65(0.43-0.99)$ \\
\hline \multicolumn{5}{|l|}{ Country of birth } \\
\hline Australia & 1996 & $36.5 \%$ & 0.110 & 1.00 (reference) \\
\hline Other, English speaking & 352 & $38.4 \%$ & & $1.03(0.77-1.38)$ \\
\hline Other, not English speaking & 605 & $41.2 \%$ & & $1.07(0.84-1.36)$ \\
\hline Unknown & 87 & {$[64.4 \%]$} & & $3.27(1.77-6.03)$ \\
\hline \multicolumn{5}{|l|}{ Lung location } \\
\hline C340 (main bronchus) & 223 & $8.5 \%$ & $<0.001$ & 1.00 (reference) \\
\hline C341 (upper lobe) & 1366 & $44.5 \%$ & & $9.26(5.51-15.56)$ \\
\hline C342 (middle lobe) & 172 & $43.0 \%$ & & $7.56(4.08-14.01)$ \\
\hline C343 (lower lobe) & 841 & $49.0 \%$ & & $11.82(6.96-20.09)$ \\
\hline C348 (overlapping) & 31 & $45.2 \%$ & & $10.26(4.05-25.99)$ \\
\hline C349 (not specified) & 407 & [10.1\%] & & $1.59(0.86-2.94)$ \\
\hline \multicolumn{5}{|l|}{ Histology type } \\
\hline Adenocarcinoma & 1014 & $56.4 \%$ & $<0.001$ & 1.00 (reference) \\
\hline Squamous cell carcinoma & 890 & $38.7 \%$ & & $0.60(0.48-0.75)$ \\
\hline Large cell carcinoma & 908 & $15.1 \%$ & & $0.15(0.12-0.20)$ \\
\hline Other & 228 & $50.4 \%$ & & $1.16(0.80-1.67)$ \\
\hline \multicolumn{5}{|l|}{ Comorbidity status } \\
\hline Absent & 1270 & $45.2 \%$ & $<0.001$ & 1.00 (reference) \\
\hline Present & 1518 & $31.2 \%$ & & $0.74(0.61-0.90)$ \\
\hline Unknown & 252 & [47.6\%] & & $1.32(0.93-1.88)$ \\
\hline
\end{tabular}

Percentages in brackets and associated raw data were excluded when deriving $P$ values. * Data source: NSW Central Cancer Registry. † Derived using Mann-Whitney $U$ test for ordinal variables and Pearson $\chi^{2}$ for nominal variables. ${ }^{23} \ddagger$ Adjusted for other variables in multiple logistic regression model, including local health districts (expressed as dummy variables). death probability after adjusting for insurance status (Box 2), the lowest socioeconomic status was predictive if insurance status was removed from the model (SHR for socioeconomic quintile 5 compared with quintile 1 , 1.31 ; 95\% CI, 1.02-1.67).

When the six border LHDs were excluded, similar results presented, although statistical significance was not quite reached for patients born outside Australia in Englishspeaking countries compared with Australian-born patients (SHR, 0.85; 95\% CI, 0.70-1.01).

Unadjusted analyses showed significantly higher probabilities of lung cancer death $(P<0.05)$ for men, outer regional areas, the most disadvantaged socioeconomic quintiles of 4 and 5, and cases with comorbidity, but statistically significant associations did not apply in the adjusted analysis (Box 2).

When the adjusted analysis was repeated for cases having a resection, hospital resection volume did not approach statistical significance as a predictor of lung cancer death $(P=0.524)$, although there was some suggestion of a decrease in SHRs with increase in annual volume to 0.94 (95\% CI, 0.65-1.37) for 9-36 resections and 0.80 (95\% CI, 0.54-1.18) for 37 or more resections.

\section{Low-risk patients}

Similar SHR patterns applied as in the full analysis to the 255 patients classified as "low risk", 181 (71.0\%) of whom had a resection. For these lowrisk cases, compared with lobectomy cases, both adjusted and unadjusted analyses showed a higher probability of lung cancer death for patients not receiving a resection (unadjusted SHR, 6.19; 95\% CI, 3.81-10.06; adjusted SHR, 14.12; 95\% CI, 7.23-27.54).

\section{Discussion}

Results indicate that between 38\% and $43 \%$ of localised NSCLC cases diagnosed in NSW residents in 2003-2007 were treated by resection, depending on whether LHDs regarded as susceptible to underrecording from cross-border treatments are included. The resection rate peaked at $59 \%$ by LHD for all cases and $71 \%$ for NSW as a whole for cases considered at low surgical risk. 
2 SHRs for cumulative probability of death from localised non-small cell lung cancer diagnosed in New South Wales, 2003-2007, according to patient and cancer characteristics, and treatment by resection*

\begin{tabular}{|c|c|c|c|}
\hline Characteristic & $\begin{array}{l}\text { No. of patients/ } \\
\text { lung cancer deaths }\end{array}$ & $\begin{array}{c}\text { Adjusted SHR } \\
(95 \% \mathrm{Cl})^{\dagger}\end{array}$ & $\begin{array}{l}\text { Adjusted } P \\
\text { for test }\end{array}$ \\
\hline \multicolumn{4}{|l|}{ Age at diagnosis (years) } \\
\hline$<60$ & $490 / 167$ & 1.00 (reference) & $<0.001$ \\
\hline $60-69$ & $832 / 366$ & $1.25(1.05-1.49)$ & \\
\hline 70-79 & 1091/585 & $1.46(1.23-1.73)$ & \\
\hline$\geqslant 80$ & $627 / 420$ & $1.86(1.54-2.24)$ & \\
\hline \multicolumn{4}{|l|}{ Sex } \\
\hline Male & $1901 / 1009$ & 1.00 (reference) & 0.068 \\
\hline Female & $1139 / 529$ & $0.90(0.81-1.01)$ & \\
\hline \multicolumn{4}{|l|}{ Public/private payment status } \\
\hline Public & 1918/1064 & 1.00 (reference) & $<0.001$ \\
\hline Private (+ Veterans' Affairs) & $1082 / 461$ & $0.76(0.68-0.86)$ & \\
\hline Unknown & $40 / 13$ & $0.52(0.27-0.98)$ & \\
\hline \multicolumn{4}{|l|}{ Remoteness (residence) } \\
\hline Major city & $1747 / 860$ & 1.00 (reference) & 0.169 \\
\hline Inner regional & $834 / 431$ & $0.92(0.78-1.07)$ & \\
\hline Outer regional & $411 / 227$ & $0.79(0.63-1.01)$ & \\
\hline Remote/very remote & $48 / 20$ & $0.62(0.36-1.07)$ & \\
\hline \multicolumn{4}{|c|}{ Socio-Economic Indexes for Areas quintile } \\
\hline 1 (least disadvantaged) & $508 / 237$ & 1.00 (reference) & 0.078 \\
\hline 2 & $502 / 229$ & $1.02(0.82-1.28)$ & \\
\hline 3 & $624 / 321$ & $1.00(0.79-1.27)$ & \\
\hline 4 & $744 / 397$ & $1.19(0.94-1.52)$ & \\
\hline 5 (most disadvantaged) & $662 / 354$ & $1.24(0.97-1.59)$ & \\
\hline \multicolumn{4}{|l|}{ Country of birth } \\
\hline Australia & 1996/1051 & 1.00 (reference) & $<0.001$ \\
\hline Other, English speaking & $352 / 178$ & $0.84(0.71-0.99)$ & \\
\hline Other, not English speaking & $605 / 298$ & $0.84(0.73-0.97)$ & \\
\hline Unknown & $87 / 11$ & $0.27(0.15-0.52)$ & \\
\hline \multicolumn{4}{|l|}{ Lung location } \\
\hline C340 (main bronchus) & 223/155 & 1.00 (reference) & 0.005 \\
\hline C341 (upper lobe) & $1366 / 643$ & $0.88(0.74-1.05)$ & \\
\hline C342 (middle lobe) & $172 / 74$ & $0.90(0.68-1.19)$ & \\
\hline C343 (lower lobe) & $841 / 372$ & $0.85(0.71-1.02)$ & \\
\hline C348 (overlapping) & $31 / 15$ & $1.08(0.65-1.80)$ & \\
\hline C349 (not specified) & $407 / 279$ & $1.19(0.97-1.46)$ & \\
\hline \multicolumn{4}{|l|}{ Histology type } \\
\hline Adenocarcinoma & $1014 / 386$ & 1.00 (reference) & $<0.001$ \\
\hline Squamous cell carcinoma & $890 / 474$ & $1.06(0.93-1.22)$ & \\
\hline Large cell carcinoma & $908 / 627$ & $1.23(1.08-1.41)$ & \\
\hline Other (includes carcinoid) & $228 / 51$ & $0.46(0.33-0.64)$ & \\
\hline \multicolumn{4}{|l|}{ Comorbidity status } \\
\hline Absent & $1270 / 588$ & 1.00 (reference) & 0.277 \\
\hline Present & $1518 / 842$ & $1.02(0.91-1.14)$ & \\
\hline Unknown & $252 / 108$ & $1.17(0.96-1.42)$ & \\
\hline \multicolumn{4}{|l|}{ Resection } \\
\hline None & $1872 / 1325$ & $5.80(4.81-6.99)$ & $<0.001$ \\
\hline Segmental & 271/38 & $0.80(0.56-1.14)$ & \\
\hline Wedge & $102 / 26$ & $1.47(1.00-2.17)$ & \\
\hline Lobectomy & $738 / 124$ & 1.00 (reference) & \\
\hline Pneumonectomy & $57 / 25$ & $2.47(1.68-3.61)$ & \\
\hline
\end{tabular}

* Data source: NSW Central Cancer Registry. $†$ Adjusted for other variables in the model, including local health districts expressed as dummy variables. SHR = subhazard ratio.
Multiple logistic regression analysis indicated that lower resection rates applied to patients older than 70 years. Although the possibility of undertreatment of older patients exists, it is likely that lower resection rates were influenced by higher surgical risk from increased frailty, especially in patients older than 80 years. Predictably, the resection rate was lower among patients with recorded comorbidity, many of whom would have been considered to have a higher surgical risk, but our measure of comorbidity related to morbid conditions and there was no statistical adjustment for less overt frailty.

Patients without private health insurance or Veterans' Affairs coverage and those from lower socioeconomic areas had significantly lower resection rates in multivariate analysis. Financial barriers may have contributed, along with educational differences and other correlates that affected service use.

Cancers located in the main bronchus had lower resection rates than those in pulmonary lobes. This has been reported elsewhere, and reflects the need for more extensive resection for central lesions for which the patient may not be operable due to inadequate cardiopulmonary reserve. ${ }^{25,26}$ Squamous cell carcinomas also had lower resection rates than adenocarcinomas, which may be due to their more central locations. ${ }^{25,26}$ Large cell cancers had a low resection rate, although these are often located peripherally, ${ }^{26}$ which may be due to less favourable prospects for curative resection, given their propensity for rapid growth and spread. ${ }^{26}$

Men had a lower resection rate, but a statistically significant difference did not remain after adjusting for age, histology type and comorbidity. Women with lung cancers have a higher proportion of adenocarcinomas, which have higher resection rates. This suggests that the difference in resection rate by sex partly reflected biological variations rather than choice. Residents of regional areas also had lower unadjusted resection rates that were not evident in the multivariate analysis, after adjusting for socioeconomic status and LHD, which may be due to lower socioeconomic 
3 Cumulative probability of death from lung cancer: localised non-small cell lung cancer cases diagnosed in New South Wales, 2003-2007*
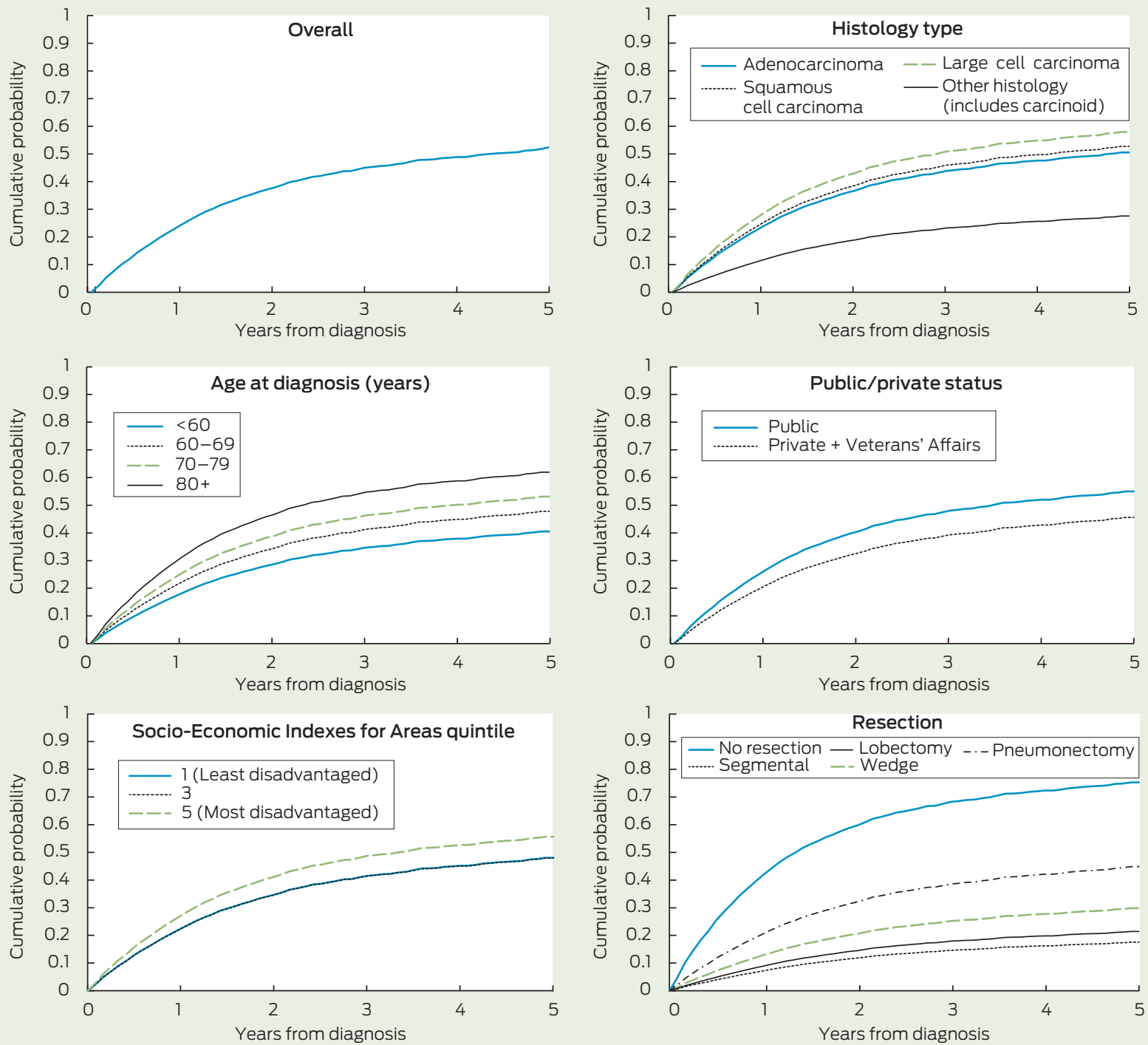

*Derived from competing risk regression including age, sex, public/private status, remoteness, socioeconomic status, local health district, country of birth, lung location of tumours, histology type, comorbidity score, and resection type as predictors of lung cancer death.

status and some undercounting due to cross-border treatment.

Financial barriers, variations in access, and other potentially modifiable barriers need to be addressed to optimise cure rates from localised NSCLC. The highest resection rate by LHD was $59 \%$, which could be used as an overall NSW target in the first instance.

Resection was associated with an approximate $70 \%$ reduction in deaths in the 5 years after diagnosis. If the low overall resection rate of $38 \%-43 \%$ were increased to equate with the highest LHD resection rate of 59\%, the proportion of all NSCLC patients dying of NSCLC in the 5 years after diagnosis would be reduced by about $10 \%$, based on the differences in probabilities of death by resection estimated in our study.

These data, and research evidence supporting clinical guidelines for resection, could be discussed at workshops of clinicians and made available through web-based communications, to promote heightened awareness of this evidence when planning treatment. ${ }^{7-10}$ It is also possible that deaths could be prevented by an increased use of lobectomies in preference to wedge resections, given the elevated risk for wedge resection. This evidence should also be discussed with clinicians.
Similar results applied when parallel analyses were undertaken of all-cause mortality as the outcome, using proportional hazards regression instead of a competing risk analysis, and when restricting cases in the analyses to those with complete data. ${ }^{23}$ While strenuous attempts were made to control for confounding, the study design was observational and it is acknowledged that potential for confounding would exist from unmeasured factors (eg, frailty, patient choice) and factors inexactly measured (eg, comorbidity). Results therefore should be regarded as a guide and their statistical precision not over-interpreted. 
Population-based radiotherapy data were not available to us, but are being assembled for future analysis. In the absence of randomised trial data, it would be useful to compare outcomes of resections, curative radiotherapy and combined treatments for localised NSCLC.

In the meantime, the results of this study are consistent with guideline recommendations that resection be used for localised NSCLC.7-10 Results indicate marked differences in probability of lung cancer death in the first 5 years from diagnosis of localised NSCLC in NSW depending on whether resection is undertaken. Potential exists to reduce numbers of deaths from lung cancer in NSCLC cases by increasing resection rates.

Competing interests: No relevant disclosures.

\section{Received 14 Mar 2014, accepted 7 Jul 2014.}

1 Australian Institute of Health and Welfare, Australasian Association of Cancer Registries.

Cancer in Australia: an overview, 2012. Canberra: AlHW, 2012. (AlHW Cat. No. CAN 70; Cancer Series No. 74.)

2 Ferlay J, Shin HR, Bray F, et al. GLOBOCAN 2008 V2.0. Cancer incidence and mortality worldwide: IARC CancerBase No. 10. Lyon: International Agency for Research on Cancer, 2010.

3 Australian Institute of Health and Welfare, Cancer Australia. Lung cancer in Australia: an overview. Canberra: AlHW, 2011. (AlHW Cat. No. CAN 58: Cancer Series No. 64.)
4 Australian Institute of Health and Welfare. Australian cancer incidence and mortality (ACIM) books. Canberra: AlHW, 2013.

5 Australian Institute of Health and Welfare. Cancer survival and prevalence in Australia: period estimates from 1982 to 2010. Canberra: AlHW, 2012. (AlHW Cat. No. CAN 65; Cancer Series No. 69.)

6 Walters S, Maringe C, Coleman MP, et al. Lung cancer survival and stage at diagnosis in Australia, Canada, Denmark, Norway, Sweden and the UK: a population-based study, 20042007. Thorax 2013; 68: 551-564.

7 Cancer Council Australia. Clinical practice guidelines for the prevention, diagnosis and management of lung cancer. Approved by the National Health and Medical Research Council. Sydney: Cancer Council Australia, 2004

8 Canadian Partnership against Cancer. Lung cancer in Canada: a supplemental system performance report. May 2011. http://www. partnershipagainstcancer.ca/wp-content/ uploads/Lung-Cancer-in-Canada-ASupplemental-System-Performance-Report. pdf (accessed Oct 2013).

9 National Comprehensive Cancer Network. Clinical practice guidelines in oncology, nonsmall cell lung cancer, version 3.2011. http:// www.nccn.org/professionals/physician_gls/ $\mathrm{pdf} / \mathrm{nscl} . \mathrm{pdf}$ (accessed Nov 2013).

10 Scott WJ, Howington J, Feigenberg S, et al. Treatment of non-small cell lung cancer stage I and stage II: ACCP evidence-based clinical practice guidelines (2nd edition). Chest 2007; 132: 234S-242S.

11 Detterbeck FC, Egan TM. Surgery for stage II non-small cell lung cancer. In: Detterbeck FC, Socinski MA, Rivera MP, Rosenman JG, editors. Diagnosis and treatment of lung cancer - an evidence based guide for the practicing clinician. Philadelphia: WB Saunders, 2001: 191-197.

12 Jones DR, Detterbeck FC. Surgery for stage I non-small cell lung cancer. In: Detterbeck FC Socinski MA, Rivera MP, Rosenman JG, editors.
Diagnosis and treatment of lung cancer - an evidence-based guide for the practicing clinician. Philadelphia: WB Saunders, 2001: 177-190.

13 Manser R, Wright G, Hart D, et al. Surgery for local and locally advanced nonsmall cell lung cancer [review]. Cochrane Collaboration: John Wiley \& Sons, 2010.

14 Tracey EA, Roder DM, Currow DC. What factors affect the odds of NSW cance patients presenting with localised as opposed to more advanced cancer? Cancer Causes Control 2012; 23: 255-262.

15 Hutchison CL, Menck HR, Burch M, Gottschalk R, editors. Cancer registry management: principles and practice. 2nd ed. Springfield, Ill: National Cancer Registrars Association, 2004.

16 Australian Institute of Health and Welfare. National health data dictionary 2012 version 16. Canberra: AlHW, 2012. (AlHW Cat. No. HWI 119.)

17 Australian Institute of Health and Welfare, Cancer Australia, Australasian Association of Cancer Registries. Cancer survival and prevalence in Australia: cancers diagnosed from 1982 to 2004. Canberra: AlHW, 2008. (AlHW Cat. No. CAN 38; Cancer Series No. 42.)

18 Australian Bureau of Statistics. Information paper: an introduction to SocioEconomic Indexes for Areas (SEIFA), 2006. Canberra: ABS, 2008. (ABS Cat. No. 2039.0.) http://www.abs.gov.au/ausstats/abs@.nsf/mf/2039.0 (accessed Jun 2013).

19 Young JL Jr, Roffers SD, Ries LAG, et al, editors. SEER summary staging manual -2000 : codes and coding instructions. NIH Pub. No. 01-4969. Bethesda, Md: National Cancer Institute, 2001.

20 Charlson ME, Pompei P, Ales KL, et al. A new method of classifying prognostic comorbidity in longitudinal studies: development and validation. J Chronic Dis 1987; 40: 373-383.

21 Smith RC, Creighton N, Lord RV, et al. Survival, mortality and morbidity outcomes after oesophagogastric cancer surgery in New South Wales, 20012008. Med J Aust 2014; 200: 408-413.

22 Bentley JP, Ford JB, Taylor LK, et al. Investigating linkage rates among probabilistically linked birth and hospitalization records. BMC Med Res Methodol 2012; 12: 149.

23 Armitage P, Berry G. Statistical methods in medical research. 2nd ed. Oxford: Blackwell Scientific Publications, 1987.

24 Fine JP, Gray RJ. A proportional hazards model for subdistribution of a competing risk. J Am Stat Assoc 1999; 94: 496-509.

25 Hjelda H, Sundstrøm S, Ødegård A, et al. [Recurrence and survival after surgical treatment of lung cancer] [Norwegian]. Tidsskr Nor Laegeforen 2010; 130: $25-28$

26 Strand T-E, Rostad H, Møller B, Norstein J. Survival after resection of primary lung cancer: a population based study of 3211 resected patients. Thorax 2006 61: 710-715. 